\title{
Development and Evaluation of Azelaic Acid Based Ethosomes for Topical Delivery for the Treatment of Acne
}

\author{
Ankita Mistry ${ }^{\star}$ and Padmini Ravikumar \\ Department of Pharmaceutics, SVKM's Dr. Bhanuben Nanavati College of Pharmacy, Vile Parle (W).Mumbai-400056. INDIA.
}

\begin{abstract}
Purpose: To design, develop and evaluate an Azelaic acid encapsulated Ethosomal formulation for acne. Methods: Encapsulated ethosomes were prepared by three methods viz. hot method, cold method and thin film hydration method. Central Composite Design was employed for optimisation of ethosomal formulations. Concentrations of phospholipid, cholesterol and ethanol were selected as independent variables and their effect on the dependent variables (Entrapment Efficiency and Drug Diffused) was studied. The optimised vesicular carriers were evaluated for vesicle size, entrapment efficiency, in-vitro and ex-vivo diffusion studies, anti-microbial activity, skin irritation studies and stability studies as per ICH guidelines. Ethosomal formulations with varying soya phosphatidylcholine, cholesterol and ethanol were prepared. Results: Vesicles were spherical, unilamellar with a smooth surface. The optimised formulation showed a vesicle size of $4.25 \pm 1.35 \mu \mathrm{m}$ and entrapment efficiency of $91.86 \pm 2.25 \%$. In-vitro and exvivo drug diffusion of the ethosomal gel was compared with a conventional gel and a marketed cream. The developed novel formulation exhibited enhanced anti-acne activity as compared to conventional gel and a marketed cream. Conclusion: We can conclude that the ethosomal formulation is an efficient vesicular carrier system for topical delivery.
\end{abstract}

Key words: Ethosomes, Azelaic acid, Composite, Vesicles, Propionibacterium acne, Topical.

\section{INTRODUCTION}

Acne vulgaris, one of the most common skin disorders, is the result of chronic inflammation of sebaceous follicles and is characterized by tender inflammatory papules and nodules mainly scattered on the face, chest, and upper back. An increase in circulating androgens at the onset of puberty stimulates the production of sebum. It is caused by cutaneous micro-organisms such as Propionibacterium acnes (P. acnes). ${ }^{1} P$. acnes itself has been shown to stimulate toll-like receptor 2 (TLR-2) activity, resulting in skin inflammation and comedogenesis. The individual lesions of
Acne vulgaris, are of three types: inflamed lesions, non-inflamed lesions, and scars. ${ }^{2}$

Topical Azelaic acid (AzA) is approved for the treatment of acne vulgaris and inflammatory (papulopustular) rosacea. Due to diverse mechanisms of action that correlate with potential therapeutic benefit, AzA has been used to treat several common dermatoses including acne vulgaris, perioral dermatitis, inflammatory rosacea, melasma, and post inflammatory hyperpigmentation. ${ }^{3}$

AzA is a naturally occurring dicarboxylic acid produced by the yeast fungus Pityrosporum ovale. Another beneficial effect of
Submission Date : 24-06-2015 Revision Date : 29-02-2016 Accepted Date : :09-03-2016

DOI: 10.5530/ijper.50.3.34 Correspondence: Ankita Mistry,

Department of Pharmaceutics, SVKM's Dr. Bhanuben Nanavati College of Pharmacy, Vile Parle (W) Mumbai-400056. INDIA. Phone no: 022-42332052 E-mail: ankitam.1208@ gmail.com

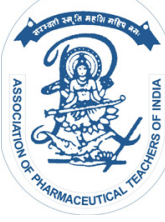

www.ijper.org 
this agent is to decrease hyper-pigmentation caused by acne. It helps scavenge reactive oxygen species, reduces expression of kallikrein-5 (KLK-5) and pro-inflammatory cathelicidins like LL-37, as well as inhibits TLR-2. It also inhibits the pigment producing enzyme tyrosinase, may reduce epidermal hyperkeratinization and has comedolytic properties and ${ }^{4}$ TLR- 2 over-activity plays a role in the pathogenesis of acne. $P$. acne is a gram-positive and propionic acid-producing bacterium that colonizes anaerobically within the hair follicles of the skin.

Drugs used to treat acne include AzA, benzoyl peroxide, clindamycin phosphate, adapalene, erythromycin, tretinoin and isotretinoin.

Limitations of conventional topical formulations include side effects like scaling, erythema, dryness, stinging, irritation, burning, itching, rash, pruritus and sunburn. To reduce side effects, novel carrier-based drug delivery systems are formulated which distribute the topical medicament gradually, reduce the irritancy of drugs and maintain better efficacy. Therefore, penetration is more efficient than non-particulate systems that provide a high local concentration.

Vesicles are an example of novel drug delivery systems which act as drug carriers to deliver entrapped drug molecules into or across the skin. They act as enhancers for the penetration of the individual lipid components into the stratum corneum and subsequently altering the inter-cellular lipid lamellae within this skin layer. Vesicles also serve as a depot for sustained release of dermally active compounds and as a rate limiting membrane barrier for the modulation of systemic absorption, therefore, providing a controlled transdermal delivery system. ${ }^{5}$

Ethosomes are phospholipid-based elastic vesicles containing $20-45 \%$ ethanol. Ethanol is a proven permeation enhancer imparting high flexibility to vesicular membrane which permits the elastic vesicles to squeeze themselves through the pores. The mechanism of penetration enhancement with the ethosomal system suggests the intercalation of ethanol into the polar head group environment resulting in increased membrane permeability. Ethosomes are reported to be more stable than liposomes because of the presence of ethanol, which provides a net negative charge on the surface thereby avoiding aggregation of vesicles due to electrostatic repulsion. ${ }^{6,7}$ Topically applied ethosomes can increase the residence time of active ingredients in the stratum corneum, epidermis and reduce the systemic absorption of drugs. All these properties allow ethosomes to permeate easily into the deeper layers of the skin and circulation where ethanol causes skin disruption which increases the lipid fluidity that allows enhanced permeation of medicament through the skin. It then fuses with skin lipids to release the medicament into deep skin layers. Ethosomes enhance the permeation of the drug through skin, disperse better, exhibit improved therapeutic efficacy and good storage stability, improved bioavailability and provide protection from toxicity. Thus, the rationale of this work is to enhance the accumulation of a model drug for acne treatment at the site of administration and achieve sustained release.

\section{The Central Composite Design (CCD)}

This is the most popular of all second-order designs and the design consists of the following three portions:

1. A complete (or a fraction of) $2 k$ factorial design whose factors' levels are coded as -1 and 1 , is called the factorial portion.

2. An axial portion consisting of $2 k$ points arranged so that two points are chosen on the axis of each control variable at a distance of $a$ from the design centre (chosen as the point at the origin of the coordinates system).

3. $n_{0}$ centre points. $^{8}$

\section{MATERIALS AND METHODS}

\section{Materials}

AzA was purchased from Otto Chemie pvt. Ltd (Mumbai), Soya phosphatidyl choline from Himedia, Cholesterol from Qualigens, Solvents like methanol, ethanol, and chloroform were procured from SD-Fine. Carbopol 934 was obtained as a gift sample from Lubrizol. Dialysis membrane was purchased from Himedia. Male Albino rats were purchased from Bharat Serum, Thane.

\section{METHODS}

\section{Preparation of Ethosomes ${ }^{9,10}$}

The methods tried for preparation of ethosomal formulations were Hot Method, Cold Method and Thin film hydration method using rotary evaporator.

\section{Hot Method}

A mixture of drug, ethanol and propylene glycol was prepared, heated at $40^{\circ} \mathrm{C}$ and the mixture was added to the phospholipid dispersion in water at $40^{\circ} \mathrm{C}$ and mixed for $30 \mathrm{~min}$ at $700 \mathrm{rpm}$.

\section{Cold Method}

The phospholipids, drug, and other lipid materials were dissolved in ethanol, in a covered vessel, at room temperature, with vigorous stirring and heated up to $30^{\circ} \mathrm{C}$ on a water bath. The water was heated to $30^{\circ} \mathrm{C}$ 
in separate vessel, and added to the above mixture and stirred for $30 \mathrm{~min}$ in a covered vessel.

\section{Thin film hydration method using rotary evaporator}

Phospholipid, cholesterol was taken in round bottom flask containing glass beads and dissolved in chloroform and methanol. The solvents were evaporated at $40^{\circ} \mathrm{C}$ by applying vacuum for 30-40 min for the film formation. The film was then hydrated by using $\mathrm{pH} 7.4$ phosphate buffer and ethanol for $1 \mathrm{~h}$ until a suspension is formed.

\section{Preparation of ethosomal gel}

AzA ethosomal vesicles with the best entrapment efficiency result were chosen for gel formulation. Specific amount of Carbopol 934 was added in minimum amount of water and left to swell for an hour. Appropriate amount of formulation incorporated to the swollen carbopol with continuous stirring until homogeneous ethosomal gel was formed. $\mathrm{pH}$ of the gel was then adjusted by adding triethanolamine (TEA) and stirred slowly.

\section{Preformulation studies}

Preformulation studies conducted include:

\section{Description}

AzA was checked for its colour and odour.

\section{Solubility studies}

AzA was added to solvents like distilled water, boiling water, methanol, ethanol, chloroform, $\mathrm{pH}$ 5.5, 5.6, 6.8, 7.4 Phosphate buffer, $\mathrm{pH}$ 6.8 Phosphate buffer $+0.5 \%$ Tween $80, \mathrm{pH} 6.8$ Phosphate buffer $+1 \%$ Tween 80 in 1:1 ratio.

\section{FTIR studies}

These studies were carried out to determine authenticity of the drug and drug-excipient compatibility using Fourier Transform Infrared Spectrophotometer (IR Affinityl, Shimadzu). $\mathrm{KBr}$ pellets were prepared of the active ingredient and the excipients.

\section{Melting point}

Melting point of the active ingredient was determined.

\section{Assay Method Development}

Potentiometric titration method (IP 2014): $0.1 \mathrm{~g}$ of API was dissolved in $10 \mathrm{ml}$ of methanol and $40 \mathrm{ml}$ of water was added. Titration was carried out with $0.1 \mathrm{M}$ sodium hydroxide $(\mathrm{NaOH})$, to determine the end point potentiometrically. Blank titration was carried out.

$1 \mathrm{~mL}$ of $0.1 \mathrm{M} \mathrm{NaOH}$ is equivalent to $0.0094115 \mathrm{~g}$ of AzA $\left(\mathrm{C}_{9} \mathrm{H}_{16} \mathrm{O}_{4}\right)$.

\section{Optimisation}

\section{Central Composite Design (CCD)}

\section{Experimental design}

A three-factor, three-level Central composite experimental design was constructed using DESIGN EXPERT ${ }^{\circledR}$ SOFTWARE (Version 9.0.0). The independent variables selected were the proportion of phospholipid, proportion of cholesterol and concentration of ethanol. Their corresponding levels and the dependent variables are shown in Table 1.

Table 2 mentions the optimised formula for Ethosomes.

\section{EVALUATION PARAMETERS}

\section{Evaluation of Ethosomes}

\section{$\%$ Drug content}

Assay was carried out in triplicates to determine the drug content of a) ethosomal suspension, b) ethosomal gel c) conventional gel. The assay was performed using potentiometric titration by the developed method.

\section{$\mathrm{pH}$}

$\mathrm{pH}$ of all formulations and gel were determined using calibrated $\mathrm{pH}$ meter.

\section{Drug Entrapment Efficiency}

Entrapment Efficiency was obtained by centrifugation technique. Ethosomal suspension was centrifuged for 2 hrs to obtain supernatant and sediment. The supernatant and sediment were analysed for drug entrapped using potentiometric titration. Entrapment Efficiency was obtained by the indirect method using supernatant and also by the direct method using the sediment.

Entrapment Efficiency was calculated using the formula:

Entrapment Efficiency (\%)=(D/DT) x 100\%

Where, $\mathrm{D}=$ Amount of drug in sediment

DT=Total amount of drug in supernatant and sediment

\section{Optical Microscopy}

The ethosomal formulation was evaluated by observing under Motic Instrument under 40x to determine its vesicle size.

\section{Vesicle size determination and Zeta Potential Measurement}

Vesicle size was determined by using a computerized inspection system viz. (Malvern Zetasizer). Sample was diluted with distilled water and vesicle size was determined. 
Zeta Potential was also determined, which indicates the charge present on the surface of vesicles.

\section{Scanning Electron Microscopy (SEM) Studies}

SEM studies were carried out to determine particle size, surface morphology and texture.

\section{Evaluation of Gels \\ Drug Content}

Required amount of gel corresponding to $0.1 \mathrm{~g}$ of $\mathrm{AzA}$ was taken in a beaker and using potentiometric titration the $\%$ drug content was obtained.

\section{Viscosity}

Viscosity of the prepared ethosomal gel was determined by Brook-field Viscometer at $25^{\circ} \mathrm{C}$ using spindle 96 .

\section{Spreadability}

Apparatus to determine spreadability consists of a fixed slide on wooded block to measure the length and an upper slide tied to weighing pan. Specific amount of ethosomal gel and blank carbopol gel was placed individually in between two glass slides and weight was added gradually to the pan. The time (seconds) required to separate the two slides, was taken as a measure of spreadability. It was calculated using formula,

$$
\mathrm{S}=\mathrm{M} . \mathrm{L} / \mathrm{T}
$$

Where, $\mathrm{S}=$ spreadability, $\mathrm{M}=$ weight tied to upper slide, $\mathrm{L}=$ length of glass slide, $\mathrm{T}=$ time taken (seconds).

\section{In-vitro drug release}

In-vitro drug release studies were performed using Franz diffusion cell. Specific amount of ethosomal gel was applied on the dialysis membrane. The receptor compartment contained ( $\mathrm{pH} 7.4$ phosphate buffer). $1 \mathrm{~mL}$ of aliquot was withdrawn at regular intervals for $12 \mathrm{hrs}$ and was replaced with phosphate buffer $\mathrm{pH}$ 7.4. Samples were analysed using potentiometric titration.

\section{Ex-vivo drug release}

Freshly excised porcine skin ear was immersed in $\mathrm{pH}$ 7.4 phosphate buffer. Ethosomal gel was placed on top of the skin facing the dermal side and studies were carried out using Franz diffusion cell. The receptor compartment contained $\mathrm{pH} 7.4$ phosphate buffer. $1 \mathrm{~mL}$ of aliquot was withdrawn at regular intervals for $12 \mathrm{hrs}$ and was replaced with pH 7.4 phosphate buffer. Samples were analysed using potentiometric titration.

\section{Anti-microbial testing}

Anti-microbial testing was carried out using the cup and plate method. The nutrient media viz. Reinforced Clostridial Agar was prepared and autoclaved for $15 \mathrm{~min}$ at $121^{\circ} \mathrm{C}$. Media was poured in the plates and allowed to solidify. A cup was made in the centre of the plate with cork borer and the culture (P. acne) was inoculated. Formulation was added in the cup. Prepared plates were placed in anaerobic condition using the anaerobic jar and were incubated at $37^{\circ} \mathrm{C}$ for $24 \mathrm{hrs}$. Ethosomal gel, conventional gel, marketed cream and pure drug were compared.

\section{Skin irritation study}

Protocol for the study was approved by Institutional Ethics Committee Approval number: CPCSEA/IAEC/ BNCP/P-46/2014.

Ethosomal gel was tested for irritation on male albino wistar rats. Dorsal side of rat skin was shaved using hair removal cream and subjected to wash out period. optimised formulation ethosomal gel was applied. Control was used and rats were observed after 24 hrs.

\section{Stability Studies}

Ethosomal suspension and gel were subjected to stability studies as per $\mathrm{ICH}$ guidelines to obtain 3 months data. Formulations were studied at $5 \pm 3{ }^{\circ} \mathrm{C}, 25^{\circ} \mathrm{C} \pm 2{ }^{\circ} \mathrm{C} /$ $60 \pm 5 \% \mathrm{RH}$ and $40^{\circ} \mathrm{C} \pm 2{ }^{\circ} \mathrm{C} / 75 \pm 5 \% \mathrm{RH}$.

\section{RESULTS}

\section{Preformulation studies \\ Description}

AzA was white in colour and odourless.

\section{Solubility studies}

The active medicament was found soluble in boiling water, methanol, ethanol, chloroform, $\mathrm{pH} 7.4$ phosphate buffer and was insoluble in $\mathrm{pH}$ 6.8 Phosphate buffer + $0.5 \%$ Tween 80, pH 6.8 Phosphate buffer $+1 \%$ Tween 80 , distilled water, $\mathrm{pH}$ 5.5, 5.6, 6.8 phosphate buffer.

\section{FTIR studies}

The frequencies of $\mathrm{AzA}$ were found at $\mathrm{C}=\mathrm{O}$ stretch $\left(1701 \mathrm{~cm}^{-1}\right)$, Broad -OH $\left(2934.6 \mathrm{~cm}^{-1}\right)$, C-O medium intensity $\left(1301.3 \mathrm{~cm}^{-1}\right)$ and O-H oop $\left(927.5 \mathrm{~cm}^{-1}\right)$ (Figure 1).

\section{Melting point}

Melting point of the active ingredient obtained was $106^{\circ} \mathrm{C} \pm 2^{\circ} \mathrm{C}$. Result obtained was in the reported range $\left(109^{\circ} \mathrm{C}-111^{\circ} \mathrm{C}\right)$.

\section{Inter-day and Intra-day precision}

$\%$ Relative Standard Deviation (\%RSD) obtained for inter-day precision was 0.33 and intra-day precision was found to be 0.48 . 


\section{Optimisation}

\section{Central Composite Design}

\section{RESPONSES}

\section{Entrapment Efficiency (E.E)}

Value of "Prob $>$ F" less than 0.0500 indicates model terms are significant.

Equation: \% E.E $=88.71-3.52 * \mathrm{X}_{1}+1.14 * \mathrm{X}_{2}+3.63 *$ $\mathrm{X}_{3}-2.30 * \mathrm{X}_{1} \mathrm{X}_{2}-1.07 * \mathrm{X}_{1} \mathrm{X}_{3}+0.18 * \mathrm{X}_{2} \mathrm{X}_{3}-12.80 * \mathrm{X}_{1}+$ $3.90 * \mathrm{X}_{2}-17.76 * \mathrm{X}_{3}$

Figure 2 mentions the ANOVA for response surface quadratic model (\%E.E)

Std. Dev.- 5.79, Mean: 75.38, C.V. \%: 7.68, PRESS: 1860.68, R-Squared: 0.9113, Adj R-Squared: 0.8314, Pred R-Square: 0.5074, Adeq Precision: 9.553

\section{Drug Diffused (D.D)}

Value of "Prob > F" less than 0.0500 indicates model terms are significant.

Equation: \% Drug Diffused $=86.78+4.4 * \mathrm{X}_{1}+0.3 *$ $\mathrm{X}_{2}-1 * \mathrm{X}_{3}-0.37 * \mathrm{X}_{1} \mathrm{X}_{2}-2.37 * \mathrm{X}_{1} \mathrm{X}_{3}-0.87 * \mathrm{X}_{2} \mathrm{X}_{3}-9.45 *$ $\mathrm{X}_{1}^{2}-1.95 * \mathrm{X}_{2}^{2}-25.45 * \mathrm{X}_{3}^{2}$

Figure 6 mentions the ANOVA for response surface quadratic model (\%D.D)

Std. Dev.- 8.86, Mean: 68.35, C.V. \%: 12.96, PRESS: 5542.73, R-Squared: 0.8811, Adj R-Squared: 0.7741, Pred R-Square: 0.1603, Adeq Precision: 7.055

\section{Results of the optimised formulation of Ethosomes} $\%$ Drug Content

\% Drug content of optimised Ethosomal formulation was found to be $97.3 \% \pm 1.3$ and that of Conventional Gel: $95.8 \%$.

$\mathrm{pH}$

The $\mathrm{pH}$ of the obtained ethosomal formulation was found to be 5.6. $\mathrm{pH}$ obtained was in the range of skin $\mathrm{pH}$ i.e 4.5 to 7.6 .

\section{Optical Microscopy}

Vesicle size obtained was in the range of $4.2-5.1 \mu \mathrm{m}$

\section{Entrapment efficiency (E.E)}

In case of Hot Method, formulations showed low entrapment efficiency in the range 35\%-43\%.

In case of Cold Method, the results obtained were not promising due to less entrapment efficiency and clarity, hence it was not chosen for further studies.
Based on the results obtained from hot method and cold method further batches was prepared by thin film hydration method using rotary vacuum evaporator.

Thin film hydration method using rotary evaporator: Entrapment efficiency of the batches tried with the above mentioned ranges of Phosphatidylcholine: Cholesterol, Ethanol and drug were obtained in the range of $55 \%-88 \%$ by direct method. Entrapment efficiency obtained for the optimised formulation was $91 \%$ by direct method and $91.24 \%$ by indirect method.

\section{Vesicle size determination and Zeta Potential Measurement}

Average vesicle size obtained was $514.3 \mathrm{~nm}$ and Polydispersity index obtained was 0.08 . Zeta Potential was found to be $-35.44 \mathrm{mV}$.

\section{Scanning Electron Microscopy (SEM)}

On characterization spherical, unilamellar vesicles with smooth surface were observed under scanning electron microscope (Figure 10).

\section{Results of Ethosomal gel}

\section{$\%$ Drug Content}

$\%$ Drug content of Ethosomal gel and Conventional Gel was found to be $98.2 \% \pm 1.2$ and $96.8 \% \pm 0.3$, respectively.

\section{Viscosity}

Viscosity of the formulated ethosomal gel was in the range 59987 to $984 \mathrm{mpas}$ at $\mathrm{rpm} 0.5$ to 100 using Spindle 96.

\section{Spreadability}

Spreadability of the prepared ethosomal gel found to be $8.4 \mathrm{~g} \mathrm{~cm} / \mathrm{sec}$ and that of Blank gel was found to be $1.14 \mathrm{~g} \mathrm{~cm} / \mathrm{sec}$.

\section{In-vitro and Ex-vivo drug release studies}

In-vitro drug release studies show an average drug diffusion of $89.6 \%$ and Ex-vivo drug release studies showed an average drug diffusion of $94.3 \%$ in 12 hrs. In comparison, in-vitro drug release and ex-vivo drug release the $\%$ drug diffused of $10 \%$ marketed cream was compared with that of ethosomal gel and conventional gel. Conventional gel (105\% in $1 \mathrm{hr}$ ) and marketed cream $(102 \%)$ showed faster release as compared to ethosomal gel (Table 3).

The formulated ethosomal gel showed sustained release as compared to conventional gel and marketed cream and in-vitro and ex-vivo results were comparable (Figure 11 and Figure 12). 


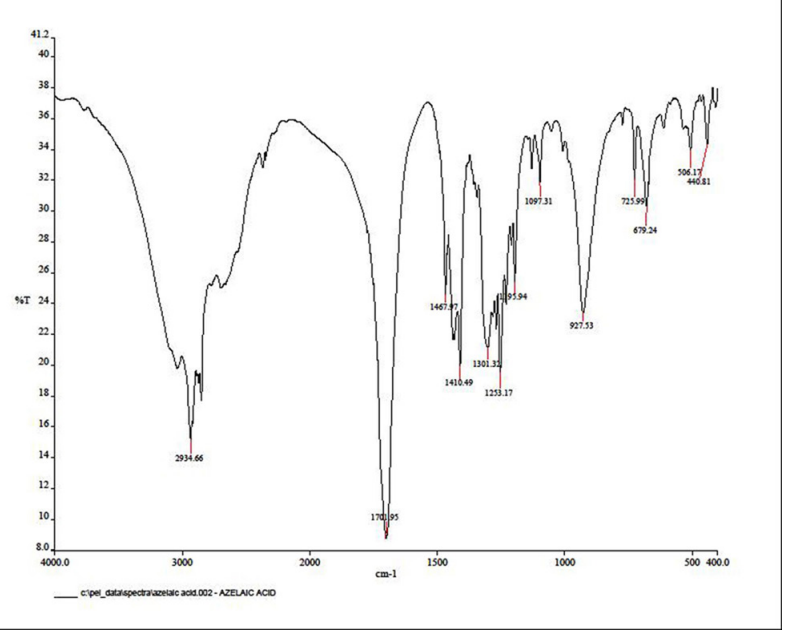

Figure 1: FTIR spectrum of Azelaic acid.

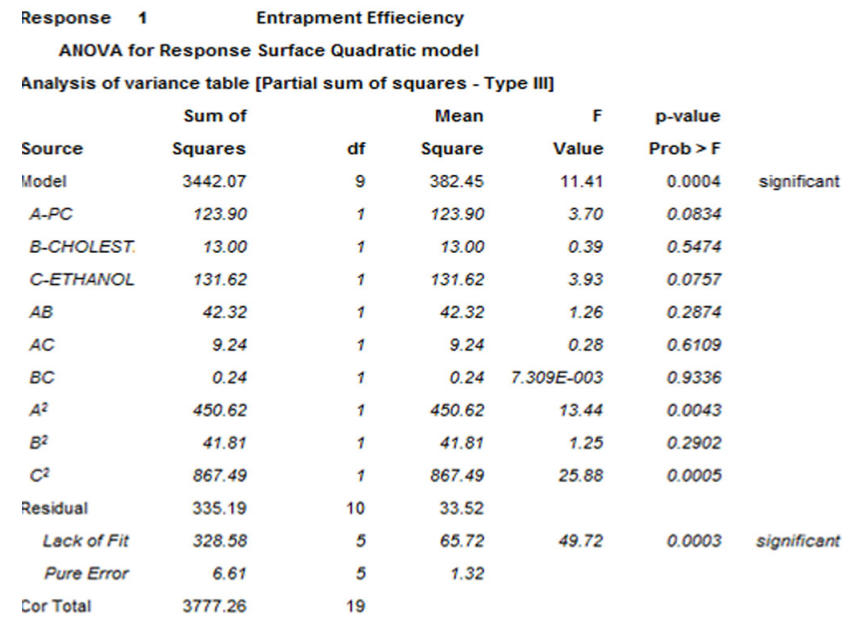

Figure 2: Anova for Response Surface Quadratic model (\% Entrapment Efficiency).

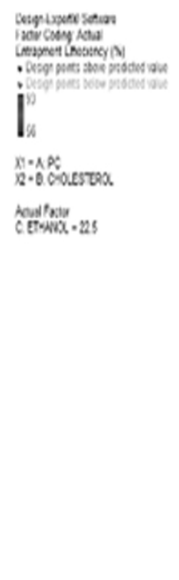

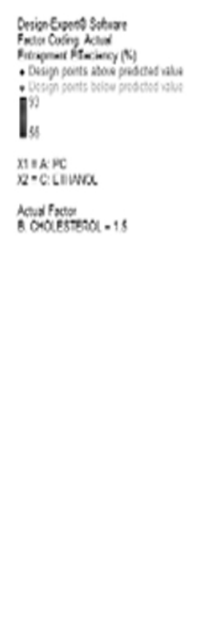

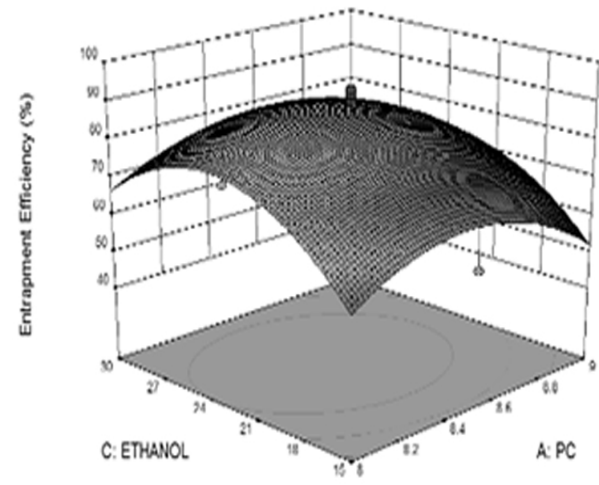

Figure 4: 3D surface plot showing effect of PC and ethanol on \%Entrapment Efficiency.
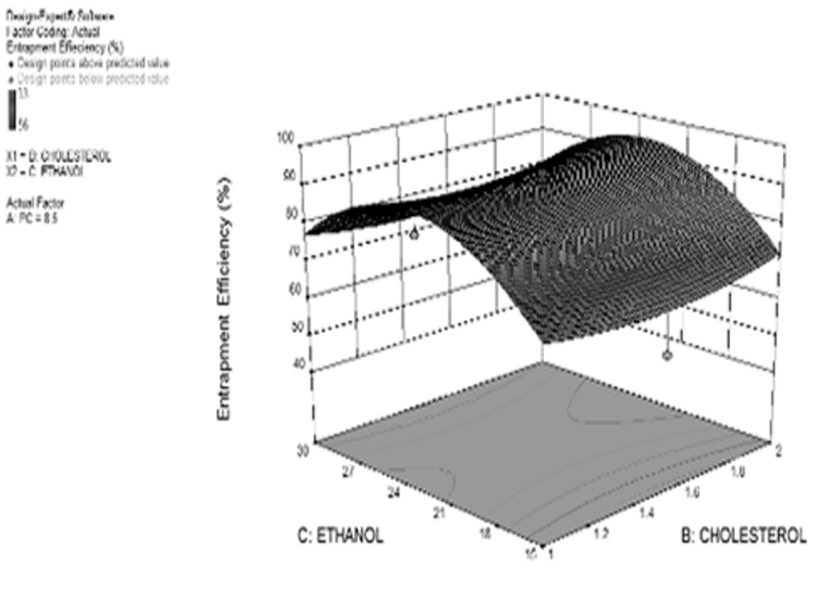

Figure 5: 3D surface plot showing effect of Cholesterol and Ethanol on \% Entrapment Efficiency.

\begin{tabular}{|c|c|c|c|c|c|c|}
\hline \multicolumn{7}{|c|}{ Analysis of variance table [Partial sum of squares - Type III] } \\
\hline & Sum of & & Mean & $\mathrm{F}$ & p-value & \\
\hline Source & Squares & df & Square & Value & Prob $>F$ & \\
\hline Model & 5815.94 & 9 & 646.22 & 8.24 & 0.0014 & significant \\
\hline$A-P C$ & 193.60 & 1 & 193.60 & 2.47 & 0.1473 & \\
\hline B-CHOLEST & 0.90 & 1 & 0.90 & 0.011 & 0.9168 & \\
\hline C-ETHANOL & 10.00 & 1 & 10.00 & 0.13 & 0.7285 & \\
\hline$A B$ & 1.13 & 1 & 1.13 & 0.014 & 0.9071 & \\
\hline$A C$ & 45.12 & 1 & 45.12 & 0.58 & 0.4657 & \\
\hline$B C$ & 6.13 & 1 & 6.13 & 0.078 & 0.7856 & \\
\hline$A^{2}$ & 245.82 & 1 & 245.82 & 3.13 & 0.1071 & \\
\hline$B^{2}$ & 10.51 & 1 & 10.51 & 0.13 & 0.7220 & \\
\hline$C^{2}$ & 1781.82 & 1 & 1781.82 & 22.71 & 0.0008 & \\
\hline Residual & 784.61 & 10 & 78.46 & & & \\
\hline Lack of Fit & 777.27 & 5 & 155.45 & 105.99 & $<0.0001$ & significant \\
\hline Pure Error & 7.33 & 5 & 1.47 & & & \\
\hline Cor Total & 6600.55 & 19 & & & & \\
\hline
\end{tabular}

Figure 3: 3D Surface plot showing effect of PC and $\%$ Cholesterol on \% Entrapment Efficiency.
Figure 6: ANOVA for Response Surface Quadratic model (\% Drug Diffused). 


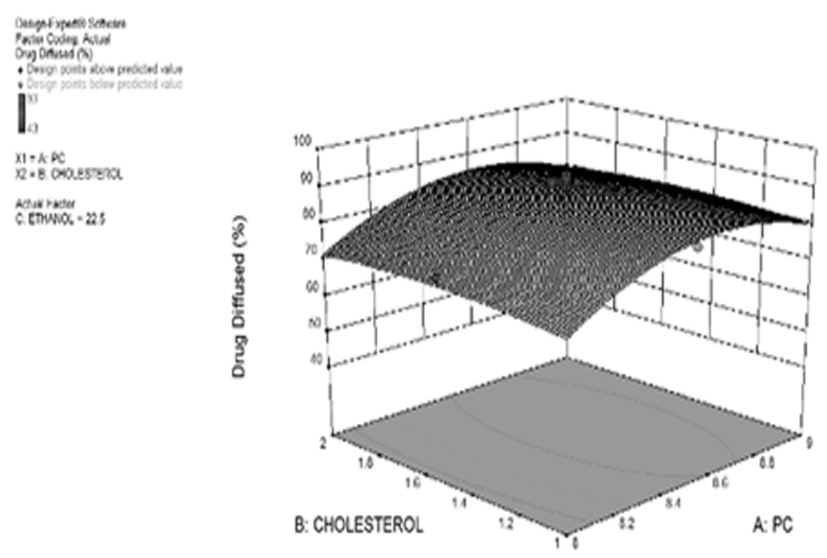

Figure 7: 3D surface plot showing effect of PC and Cholesterol on \% Drug Diffused.

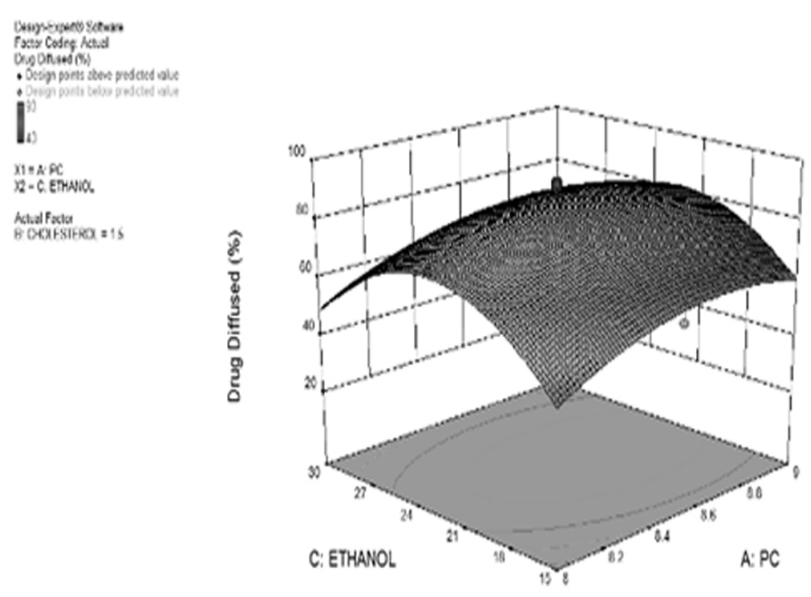

Figure 8: 3D surface plot showing effect of $P C$ and Ethanol on $\%$ Drug Diffused.

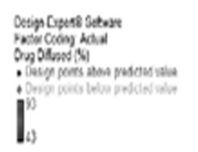

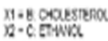
widisia

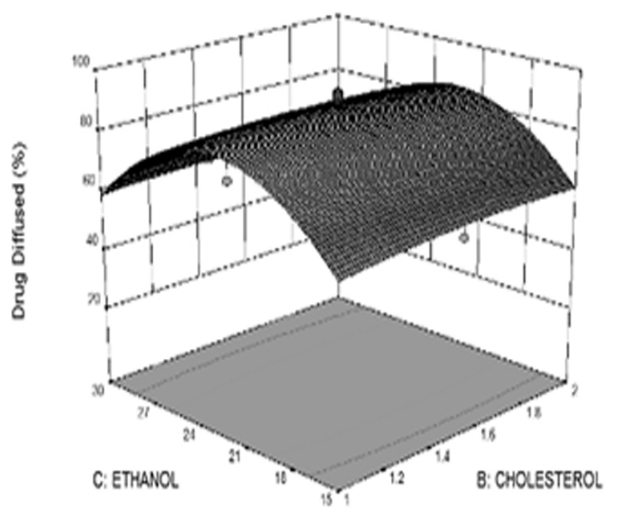

Figure 9: 3D surface plot showing effect of Ethanol and Cholesterol on \% Drug Diffused.

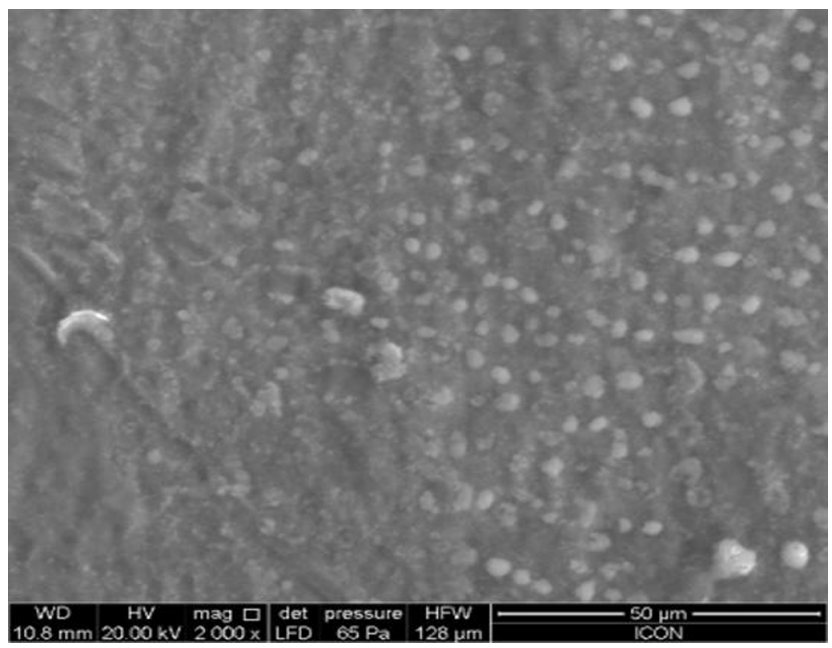

Figure 10: SEM image of Ethosomal Formulation.

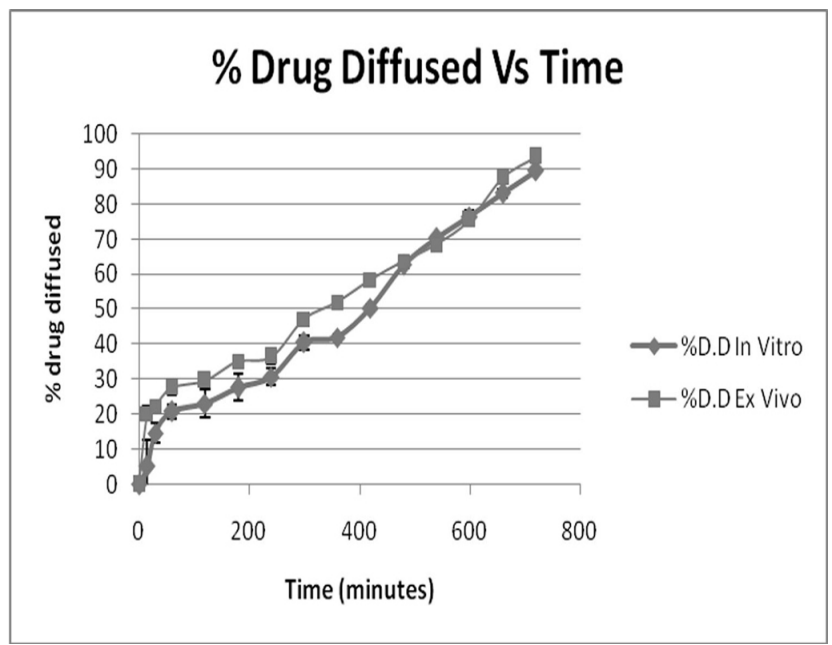

Figure 11: \% Drug diffused of Ethosomal gel (In vitro and Ex vivo).

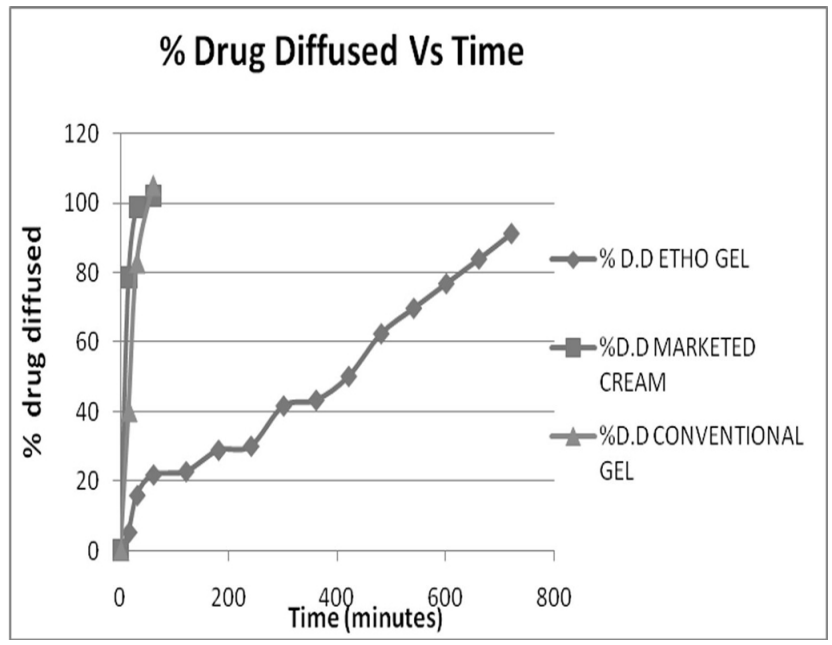

Figure 12: Comparison of ethosomal gel with marketed cream and conventional gel. 


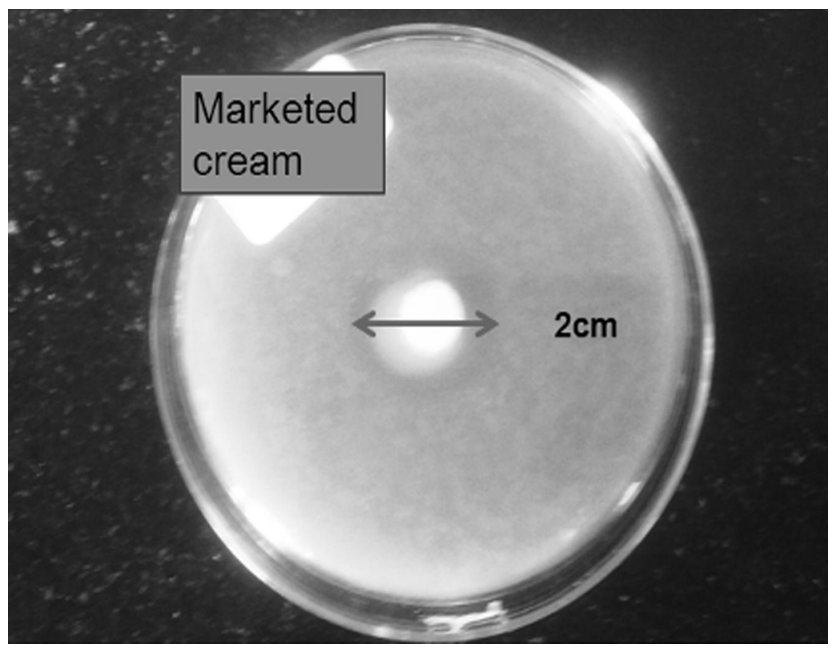

Figure 13: Zone of Inhibition of Marketed cream.

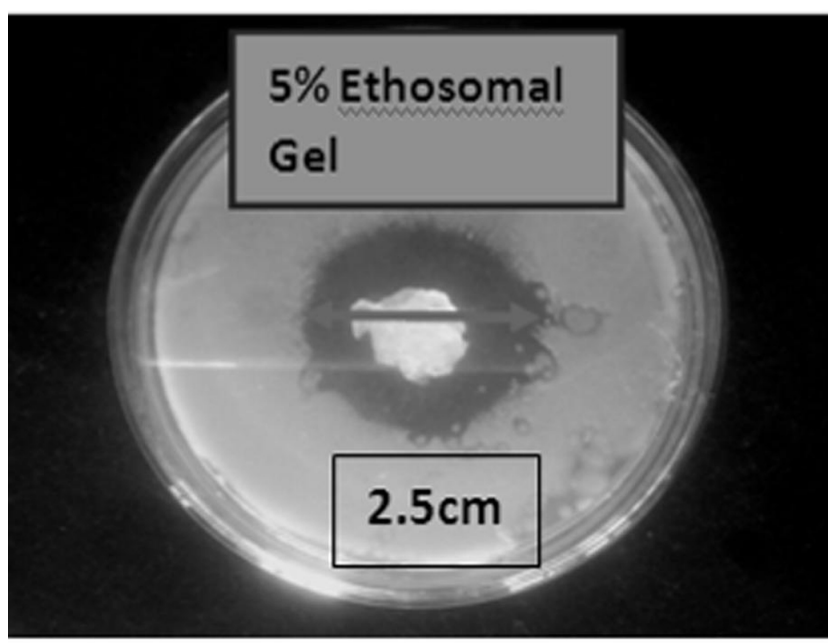

Figure 14: Zone of Inhibition of 5\% ethosomal gel.

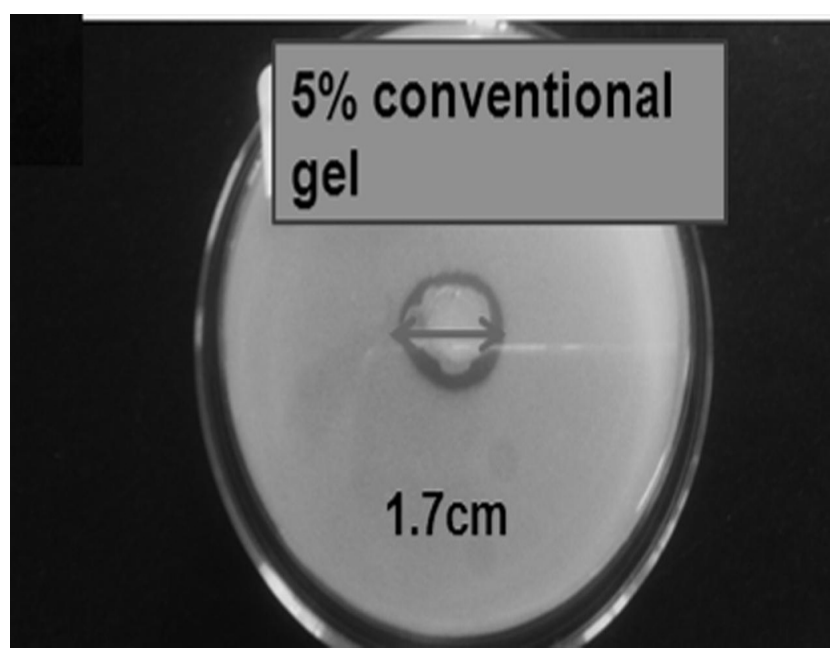

Figure 15: Zone of Inhibition of 5\% conventional gel.

\section{Kinetic Modelling}

In-vitro drug release profile of ethosomal gel showed that it follows zero order kinetics as its $\mathrm{R}^{2}$ value was closest to unity i.e 0.9819. Ex-vivo drug release profile of ethosomal gel also was found to follow zero order kinetics having $\mathrm{R}^{2}$ value as 0.9643 which is closest to unity.

\section{Determination of Flux}

Diffusion flux (J) measures the amount of substance that will flow through a small area during a small time interval. Flux was obtained from the slope values plotted for amount diffused per unit area against time. Flux of Ethosomal gel was found to be $25.54 \mathrm{mg} / \mathrm{cm}^{2} / \mathrm{hr}$, that of conventional gel was $20.6 \mathrm{mg} / \mathrm{cm}^{2} / \mathrm{hr}$ and marketed cream was $16.30 \mathrm{mg} / \mathrm{cm}^{2} / \mathrm{hr}$.

\section{Anti-microbial testing}

Zone of inhibition of the formulations were found as follows:

Marketed Cream $=2 \mathrm{~cm}$ (Figure 13)

$5 \%$ Ethosomal Gel $=2.5 \mathrm{~cm}$ (Figure 14)

$5 \%$ Conventional gel $=1.7 \mathrm{~cm}$ (Figure 15$)$

\section{Skin irritation study}

Ethosomal gel showed no reddening and inflammation after 24 hrs of skin irritation study.

\section{Stability Studies}

Table 4 mentions Stability data of Ethosomal Suspension and Ethosomal Gel.

\section{DISCUSSION}

\section{Preformulation Studies FTIR studies}

The observed frequencies were not affected when AzA was combined with phospholipid and cholesterol. From the results obtained it can be concluded that the active ingredient is compatible with the excipients without interaction.

\section{Melting point}

Results conclude that AzA is authentic.

\section{Inter-day and Intra-day precision}

Inter-day precision and Intra-day precision was found to be less than 2. This indicates that the developed method is precise and reliable to use. 
Table 1: Observed response in central composite design for Azelaic acid ethosomal formulation

\begin{tabular}{|c|c|c|c|c|}
\hline \multicolumn{3}{|c|}{ Independent Variables } & \multicolumn{2}{|c|}{ Response (Dependent Variables) } \\
\hline $\begin{array}{l}\text { X1: Phosphatidyl } \\
\text { Choline (PC) }\end{array}$ & X2: Cholesterol & $\begin{array}{c}\text { X3: Ethanol } \\
\%\end{array}$ & $\begin{array}{c}\text { Drug diffused } \\
\%\end{array}$ & $\begin{array}{c}\text { Entrapment } \\
\text { Efficiency } \\
\%\end{array}$ \\
\hline 8.5 & 1.5 & 30 & 51 & 76.68 \\
\hline 8.5 & 2 & 22.5 & 73 & 90 \\
\hline 8.5 & 1.5 & 22.5 & 90 & 93 \\
\hline 9 & 1 & 30 & 58 & 62.5 \\
\hline 8 & 1 & 30 & 43 & 65.6 \\
\hline 8.5 & 1.5 & 15 & 58 & 56 \\
\hline 8 & 2 & 30 & 51 & 72.5 \\
\hline 8 & 1 & 15 & 43 & 60 \\
\hline 8.5 & 1.5 & 22.5 & 92 & 93 \\
\hline 8.5 & 1 & 22.5 & 83 & 86 \\
\hline 9 & 2 & 30 & 53 & 60 \\
\hline 8 & 1.5 & 22.5 & 75 & 77.6 \\
\hline 8.5 & 1.5 & 22.5 & 93 & 92 \\
\hline 9 & 2 & 15 & 66 & 58 \\
\hline 8.5 & 1.5 & 22.5 & 91 & 91.5 \\
\hline 8.5 & 1.5 & 22.5 & 92 & 90 \\
\hline 8 & 2 & 15 & 43 & 66 \\
\hline 8.5 & 1.5 & 22.5 & 90 & 91.2 \\
\hline 9 & 1.5 & 22.5 & 66 & 65 \\
\hline 9 & 1 & 15 & 56 & 61 \\
\hline
\end{tabular}

Table 2 : Optimised formula for Ethosomes

\begin{tabular}{|c|c|}
\hline Ingredients & Quantity taken \\
\hline Azelaic acid & $0.75 \%$ \\
\hline Soya phoshatidyl choline & $0.85 \%$ \\
\hline Cholesterol & $0.15 \%$ \\
\hline Chloroform & $37.5 \mathrm{ml}$ \\
\hline Methanol & $12.5 \mathrm{ml}$ \\
\hline Ethanol & $22.5 \mathrm{ml}$ \\
\hline $\mathrm{pH} 7.4$ Phosphate Buffer & q.s $100 \mathrm{ml}$ \\
\hline
\end{tabular}

\section{Optimisation}

\section{Central Composite Design}

\section{RESPONSES}

\section{\% Entrapment Efficiency}

From Figure 3 and based on the $\mathrm{p}$ value of phosphatidylcholine (PC) and cholesterol, PC having lesser $\mathrm{p}$ value of 0.0834 than $\mathrm{p}$ value of cholesterol i.e 0.5474 which indicates PC has more effect on the $\%$ E.E. It was found that with increase in proportion of PC from 8 to
8.5, the $\%$ E.E significantly increased from $60 \%$ to $93 \%$ (Table 1) with lesser proportion of cholesterol. However, a further increase in proportion of PC to 9 led to a significant decrease in $\%$ E.E to $58 \%$, this may be due to the leakage of excess drug from the vesicular structure.

From Figure 4 and based on the p value of PC and ethanol, ethanol having lesser $\mathrm{p}$ value of 0.0765 than $\mathrm{p}$ value of PC i.e 0.0834 which indicates ethanol has more effect on the $\%$ E.E. It was found that with increase in ethanol concentration from $15 \%$ to $22.5 \%$, the $\%$ E.E significantly increased from $56 \%$ to $93 \%$ with lesser 


\begin{tabular}{|c|c|c|c|c|}
\hline $\begin{array}{c}\text { Time } \\
\text { (Minutes) }\end{array}$ & $\begin{array}{l}\% \text { D.D of } 5 \% \text { Ethosomal gel (In- } \\
\text { vitro) } \pm \text { Standard deviation }\end{array}$ & $\begin{array}{c}\% \mathrm{D} . \mathrm{D} \text { of } 5 \% \text { Ethosomal } \\
\text { gel }(\text { Ex-vivo) } \pm \text { Standard } \\
\text { deviation }\end{array}$ & $\begin{array}{l}\text { \%D.D marketed } \\
\text { cream } \pm \text { Standard } \\
\text { deviation }\end{array}$ & $\begin{array}{c}\% \text { D.D conventional } \\
\text { gel } \pm \text { Standard } \\
\text { deviation }\end{array}$ \\
\hline 0 & 0 & 0 & 0 & 0 \\
\hline 15 & $5.31 \pm 0.13$ & $20.25 \pm 0.41$ & $78.5 \pm 0.52$ & $40 \pm 1.3$ \\
\hline 30 & $14.73 \pm 1.11$ & $22.36 \pm 0.45$ & $98.6 \pm 1$ & $82.8 \pm 0.8$ \\
\hline 60 & $20.9 \pm 0.57$ & $27.72 \pm 0.38$ & $102 \pm 0.2$ & $105 \pm 0.6$ \\
\hline 120 & $23.16 \pm 0.49$ & $29.76 \pm 0.56$ & - & - \\
\hline 180 & $27.73 \pm 1.11$ & $35.17 \pm 0.71$ & - & - \\
\hline 240 & $30.83 \pm 1.17$ & $36.53 \pm 0.26$ & - & - \\
\hline 300 & $40.5 \pm 0.96$ & $47.18 \pm 1.05$ & - & - \\
\hline 360 & $42 \pm 0.90$ & $51.97 \pm 1$ & - & - \\
\hline 420 & $50.5 \pm 0.40$ & $58.47 \pm 0.81$ & - & \\
\hline 480 & $62.5 \pm 0.67$ & $63.73 \pm 1$ & - & - \\
\hline 540 & $70.26 \pm 0.67$ & $68.4 \pm 0.8$ & - & - \\
\hline 600 & $76.43 \pm 0.75$ & $75.53 \pm 0.53$ & - & - \\
\hline 660 & $83.2 \pm 1.45$ & $87.52 \pm 0.93$ & - & - \\
\hline 720 & $89.6 \pm 1.09$ & $93.44 \pm 0.5$ & - & - \\
\hline
\end{tabular}

\begin{tabular}{|c|c|c|c|c|c|c|}
\hline Parameters & \multicolumn{3}{|c|}{ Initial } & \multicolumn{3}{|c|}{ After 3 months } \\
\hline Stability Conditions & $5 \pm 3^{\circ} \mathrm{C}$ & $\begin{array}{l}25^{\circ} \mathrm{C} \pm 2^{\circ} \mathrm{C} / \\
60 \pm 5 \% \mathrm{RH}\end{array}$ & $\begin{array}{l}40^{\circ} \mathrm{C} \pm 2^{\circ} \mathrm{Cl} \\
75 \pm 5 \% \mathrm{RH}\end{array}$ & $5 \pm 3^{\circ} \mathrm{C}$ & $\begin{array}{l}25^{\circ} \mathrm{C} \pm 2^{\circ} \mathrm{C} / \\
60 \pm 5 \% \mathrm{RH}\end{array}$ & $\begin{array}{l}40^{\circ} \mathrm{C} \pm 2^{\circ} \mathrm{C} / \\
75 \pm 5 \% \mathrm{RH}\end{array}$ \\
\hline \multicolumn{7}{|c|}{ Ethosomal Suspension } \\
\hline Vesicle size $(\mu \mathrm{m})$ & $1-4$ & $2-6$ & $3-8$ & $1-6$ & $2-8$ & Coalescence \\
\hline $\begin{array}{l}\% \text { Entrapment } \\
\text { Efficiency }\end{array}$ & 76.4 & 91.86 & 58 & 60 & 88.2 & 48 \\
\hline Redispersibility & Good & Good & Moderate & Good & Good & Poor \\
\hline \multicolumn{7}{|c|}{ Ethosomal Gel } \\
\hline Appearance & $\begin{array}{l}\text { Pale Yellow, } \\
\text { smooth gel }\end{array}$ & $\begin{array}{l}\text { Pale Yellow, } \\
\text { smooth gel }\end{array}$ & $\begin{array}{l}\text { Pale Yellow, } \\
\text { smooth gel }\end{array}$ & $\begin{array}{l}\text { Pale Yellow, } \\
\text { smooth gel }\end{array}$ & $\begin{array}{l}\text { Pale Yellow, } \\
\text { smooth gel }\end{array}$ & $\begin{array}{l}\text { Pale Yellow, } \\
\text { smooth gel }\end{array}$ \\
\hline \%Drug Diffused & $\begin{array}{l}83.2 \% \text { in } \\
11 \text { hours }\end{array}$ & $\begin{array}{l}89.6 \% \text { in } \\
12 \text { hours }\end{array}$ & $\begin{array}{l}82.1 \% \text { in } \\
9 \text { hours }\end{array}$ & $\begin{array}{c}76.5 \% \text { in } 9 \\
\text { hours }\end{array}$ & $\begin{array}{l}81.6 \% \text { in } \\
11 \text { hours }\end{array}$ & $\begin{array}{l}75.4 \% \text { in } \\
6 \text { hours }\end{array}$ \\
\hline \%Drug Content & $93 \%$ & $98.25 \%$ & $91.5 \%$ & $94.3 \%$ & $96.3 \%$ & $89.8 \%$ \\
\hline
\end{tabular}

proportion of PC. However, a further increase in ethanol concentration to $30 \%$ led to a significant decrease in $\%$ E.E to $60 \%$, which may be due to the leakage of excess drug from the vesicular structure.

From Figure 5 and based on the $\mathrm{p}$ value of cholesterol and ethanol, ethanol having lesser $\mathrm{p}$ value of 0.0756 than $\mathrm{p}$ value of Cholesterol i.e 0.5474 , which indicates ethanol has more effect on the \%E.E. It was found that with increase in ethanol concentration from 15\% to $22.5 \%$, the $\%$ E.E significantly increased from $56 \%$ to $93 \%$ with lesser proportion of cholesterol. However, a further increase in ethanol concentration to $30 \%$ led to a significant decrease in $\%$ E.E to $60 \%$, this may be due to the leakage of excess drug from the vesicular structure.

\section{\% Drug Diffused}

From Figure 7 and based on the p value of PC and cholesterol, PC having lesser $\mathrm{p}$ value of 0.1472 than $\mathrm{p}$ value of cholesterol that is 0.9168 which indicates PC has more effect on the \%D.D. It was found that with increase in proportion of PC from 8 to 8.5 , the $\% \mathrm{D} . \mathrm{D}$ 
significantly increased from $43 \%$ to $93 \%$ with lesser proportion of cholesterol. However, a further increase in proportion of $\mathrm{PC}$ to 9 led to a significant decrease in $\%$ D.D to $53 \%$.

From Figure 8 and based on the p value of PC and ethanol, both exhibit an effect with ethanol having a larger effect on the \% D.D. It was found that with increase in ethanol concentration from $15 \%$ to $22.5 \%$, the $\%$ D.D significantly increased from $43 \%$ to $93 \%$ with lesser proportion of PC. However, a further increase in ethanol concentration to $30 \%$ led to a significant decrease in \%D.D to $51 \%$.

From Figure 9 and based on the p value of cholesterol and ethanol, ethanol having lesser $\mathrm{p}$ value of 0.7285 than $\mathrm{p}$ value of Cholesterol i.e 0.9168 , which indicates ethanol has more effect on the \%D.D. It was found that with increase in ethanol concentration from 15\% to $22.5 \%$, the $\%$ D.D significantly increased from $43 \%$ to $93 \%$ with lesser proportion of cholesterol. However, a further increase in ethanol concentration to $30 \%$ led to a significant decrease in $\%$ D.D to $51 \%$.

Fitting of the data for observed responses to various models; it was observed that the best-fitted model for the two dependent variables was quadratic model. Higher values of the standard error (SE) for coefficients indicate the quadratic (non-linear) nature of the relationship. A positive value in regression equation for a response represents an effect that favours the optimisation (synergistic effect), while a negative value indicates an inverse relationship (antagonistic effect) between the factor and the response.

From all the above figures, the effect of PC, Cholesterol and ethanol on \% Entrapment Efficiency and \% Drug Diffused was obtained from the Design Expert software. From the experimental data a maximum of $92 \%$ Entrapment efficiency and 91\% Drug Diffused was obtained when quantities of phosphatidylcholine, cholesterol, and ethanol were $0.85 \%, 0.15 \%$ and $22.5 \%$ respectively.

\section{DISCUSSION OF THE FORMULATION OF ETHOSOMES AND ETHOSOMAL GEL}

\section{Vesicle size determination and Zeta Potential Measurement}

Results obtained indicate negative charge present on the surface of ethosomes.

\section{Viscosity}

Viscosity was found to decrease with increase in $\mathrm{rpm}$ indicating a Non-Newtonian flow.

\section{Spreadability}

Spreadability of the ethosomal gel was found to be better than the blank gel indicating ethosomal gel is having good spreadability.

\section{In-vitro and Ex-vivo Drug Release Studies}

The formulated ethosomal gel showed sustained release as compared to conventional gel and marketed cream and in-vitro and ex-vivo results were comparable.

Flux of Ethosomal gel was found to be better than conventional gel and marketed cream. Incorporation of drug in ethosomes and presence of ethanol as a permeation enhancer were responsible for enhancement of flux.

\section{Anti-microbial testing}

Results of activity tests indicate that the, ethosomal gel of varied strengths viz 5\% and 10\% showed better zone of inhibition as compared to conventional gel and marketed cream which indicates that the ethosomal gels are more efficient and reliable than conventional gel and marketed cream. Out of $5 \%$ and $10 \%$ strengths, $5 \%$ Ethosomal gel gave more promising results.

\section{Skin irritation study}

The ethosomal gel prepared was found to be non-irritant to the skin.

\section{Stability Studies}

Ethosomal suspension: Redispersibility and appearance was found to be good when stored at $5^{\circ} \mathrm{C}$, sedimentation was observed at $25^{\circ} \mathrm{C}$ and phase separation was observed at $40^{\circ} \mathrm{C}$ at the end of 3 months. In case of vesicle size, no drug leakage was observed after 3 months, vesicle size was found to be increased at $5^{\circ} \mathrm{C}$ and at higher temperature coalescence was observed. There was a marked difference in \% Entrapment Efficiency at $5^{\circ} \mathrm{C}$ and $40^{\circ} \mathrm{C}$, whereas formulation at $25^{\circ} \mathrm{C}$ showed very less difference in \% Entrapment Efficiency.

Ethosomal Gel: Appearance was unchanged at the end of 3 months and there was no marked difference in $\%$ drug content. In case of $\%$ drug content, maximum amount of drug was released in 6 hrs; this may be because of high coalescence due to leakage of drug.

\section{CONCLUSION}

Ethosomal formulations of AzA were successfully prepared, optimised and evaluated. Thin film hydration method exhibited good results in terms of \% Entrapment efficiency, $\%$ Drug diffused. Vesicle size obtained was suitable. Ethosomal gel prepared was superior and efficient as compared to conventional formulations 
based on the in-vitro, ex-vivo release profiles and antimicrobial activity. Also, formulated gels provided sustained release of the medicament. The dosage form prepared was non-irritant to the skin and therefore, can be used successfully as a topical formulation.

AzA vesicular based delivery systems are hence promising in the treatment of acne and vesicular systems can be employed topically in the treatment of various skin disorders.

\section{ACKNOWLEDGEMENT}

I wish to thank SVKMs Dr. Bhanuben Nanavati College of Pharmacy for the facilities provided. The authors are thankful to Mr. Kiran Bhotkar (Icon Analytical Equipment Pvt Ltd, Mumbai for SEM results. We are thankful to Lubrizol for providing carbopol as a gift sample.

\section{CONFLICTS OF INTEREST}

No conflict of interest.

\section{ABBREVIATION USED}

AZA: Azelaic acid; P. acne: Propionibacterium acne; TLR-2: Toll-like receptor 2; KLK-5: Kallikrein-5; CCD: Central composite design; FTIR: Fourier Transform Infrared Spectrophotometer; IP: Indian Pharma- copoeia; $\mathrm{KBr}$ : Potassium bromide; $\mathbf{N a O H}$ : Sodium hydroxide; SEM: Scanning electron microscopy; ICH: International Conference on Harmonisation; RH: Relative humidity; RSD: Relative standard deviation; E.E: Entrapment efficiency; D.D: Drug diffused; ANOVA: Analysis of variance; PC: Phosphatidylcholine; TEA: Triethanolamine; SE: Standard error.

\section{REFERENCES}

1. Hsieh MF, Chen $\mathrm{CH}$. Review: Delivery of pharmaceutical agents to treat acne vulgaris: current status and perspectives. J Med Biol Eng. 2011;32(4):215-24. http://dx.doi.org/10.5405/jmbe.901

2. Amrita G, Greeshma N, Deepa M, Poornima EH. Review on Anti-Acne Potential of Medicinal Plant Extracts against Propionibacterium Acnes. Int $\mathrm{J}$ Pharm Bio Sci. 2012;3(3):987-97.

3. Del Rosso JQ. The use of topical azelaic acid for common skin disorders other than inflammatory rosacea. Cutis. 2006;77(2 Suppl):22-4. PMid:16566285.

4. Zeichner J. New Insights into Azelaic Acid. Practical Dermatology. 2013;45-6.

5. Prasanthi D, Lakshmi PK. Vesicles-Mechanism of Transdermal Permeation: A Review, Asian J. Pharm. Clin Res. 2012;5(1):18-25.

6. Nikalje P, Tiwari S. Ethosomes: A Novel Tool for Transdermal Drug Delivery. Int J Res Pharm Sci . 2012;2(1):1-20.

7. Verma P, Pathak K. Therapeutic and cosmeceutical potential of ethosomes: An overview. J Adv Pharm Tech Res. 2010;1(3):274-82. http://dx.doi. org/10.4103/0110-5558.72415 ; PMid:22247858 PMCid:PMC3255417

8. Khuri Al, Mukhopadhyay S. Response surface methodology. WIREs Computational Statistics. 2010;2:128-49. http://dx.doi.org/10.1002/wics.73 .

9. Keerthi A, Srujan KM, Dr Subrahmanyam KV. Formulation of Ethosomal Gel for Transdermal Delivery of Tramadol Hydrochloride. IJIPSR. 2013;1(2):281-95.

10. Bhasin V, Yadav H, Markandeywar T, Murthy RSR. Ethosomes: The Novel Vesicles for Transdermal Drug Delivery. IJPI's Journal of Pharmaceutics and Cosmetology. 2011;2(7):68-80.

\section{PICTORIAL ABSTRACT}

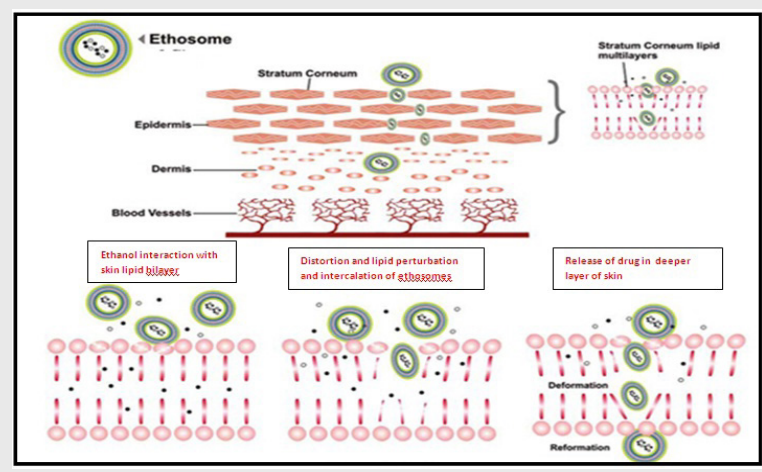

\section{SUMMARY}

- Azelaic acid ethosomes were formulated for the treatment of acne.

- Encapsulated ethosomes were prepared by three methods viz. hot method, cold method and thin film hydration method.

- Formulated ethosomes were optimised using central composite design.

- The optimised formulation showed a spherical, unilamellar vesicle of size $4.25 \pm 1.35 \mu \mathrm{m}$ and entrapment efficiency of $91.86 \pm 2.25 \%$.

- Optimized formula was used for the formulation of ethosomal gel.

- The developed novel formulation exhibited enhanced anti-acne activity, in-vitro, ex-vivo release profiles as compared to conventional gel and a marketed cream.

- The developed azelaic acid based ethosomal gel was found to be stable from the 3 months data obtained.

- AzA vesicular based delivery systems are hence promising in the treatment of acne.

- Vesicular systems thus can be employed topically in the treatment of various skin disorders. 